\title{
Chemical injuries of the eye
}

\author{
Jason M. Kwok MD, Hall F. Chew MD
}

Cite as: CMAJ 2019 September 16;191:E1028. doi: 10.1503/cmaj.190428

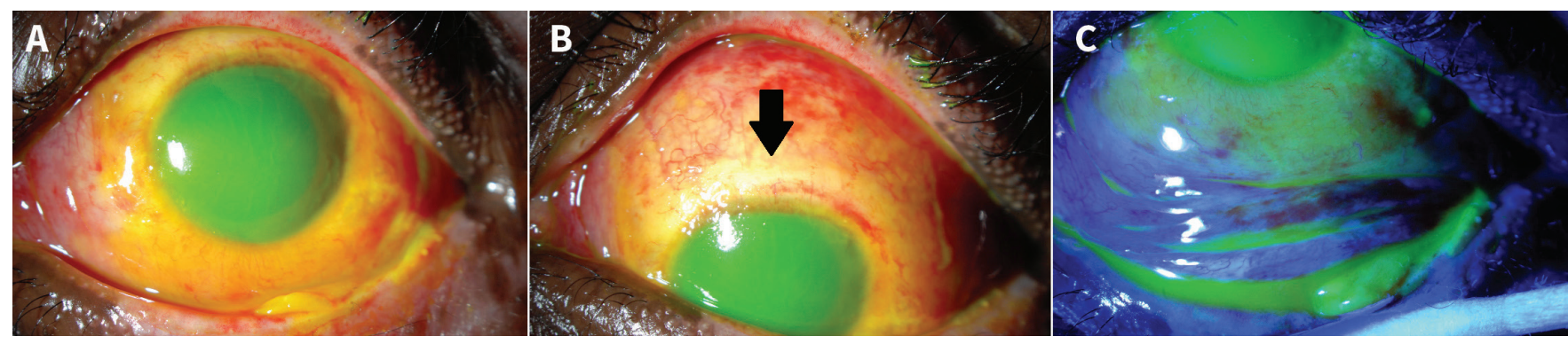

Figure 1: A) Slit-lamp examination using fluorescein stain of a left eye after sulfuric acid injury from an automobile battery explosion, showing extensive epithelial damage of the entire cornea and corneal opacification. B) Same eye in a downward gaze with the upper lid lifted to show superior corneal limbal ischemia (arrow). C) Same eye in an upward gaze re-examined under a cobalt blue filter: the fluorescein uptake and staining of both the cornea and the surrounding conjunctiva are indicative of damage to these structures.

1 A chemical injury to the eye can cause irreversible visual impairment Chemical injuries involving the eye account for $11.5 \%-22.1 \%$ of ocular trauma. They occur primarily in industrial and agricultural settings. ${ }^{1,2}$

\section{2}

\section{Early treatment with irrigation is key}

Irrigation with isotonic solutions (e.g., normal saline and lactated Ringer solution) or clean water should be started immediately after chemical exposure and continued until the patient arrives at the hospital. In hospital, irrigation is continued until the $\mathrm{pH}$ of the ocular surface is close to 7 . The level of $\mathrm{pH}$ is measured by exposing the affected ocular tissue to $\mathrm{pH}$ indicators like universal paper and should be rechecked at regular time intervals after irrigation to confirm stability. ${ }^{2,3} \mathrm{~A}$ change in $\mathrm{pH}$ can signify the presence of retained particulate chemicals, which may be missed if eyelid eversion is not performed.

\section{3}

\section{The extent of chemical injury is often dependent on the agent}

Injuries caused by alkaline agents occur more frequently and are usually more severe than those caused by acidic agents. ${ }^{2} \mathrm{~A}$ higher index of suspicion should be employed when assessing injuries caused by alkaline agents because potent alkalis can perforate the cornea in less than 15 seconds (e.g., ammonia and lye).,2,3

\section{4}

Severe ocular chemical injuries may require urgent treatment

by an ophthalmologist

Serious ocular chemical injuries are characterized by corneal opacification (Figure 1A), ischemia to the margin of the cornea (Figure 1B, black arrow) and extensive conjunctival involvement (Figure 1C). In these cases, surgical interventions may be performed in the acute setting, including débridement of necrotic tissue or amniotic membrane transplantation. ${ }^{1-5}$

\section{5}

\section{Long-term ocular complications may arise after chemical injury}

Complications of chemical injuries include glaucoma, dry eye disease, limbal stem cell deficiency (grey arrow, supplementary figure, Appendix 1, available at www.cmaj.ca/lookup/suppl/ doi:10.1503/cmaj.190428/-/DC1), and scarring involving the eyelids, conjunctiva and cornea. Although conservative management with eye drops is typically used initially, some serious injuries, in particular corneal ulceration or perforation, may require surgical intervention with limbal stem cell autograft or corneal transplantation to restore vision and alleviate symptoms. ${ }^{2,3,5}$

\section{References}

1. Clare G, Suleman H, Bunce C, et al. Amniotic membrane transplantation for acute ocular burns. Cochrane Database Syst Rev 2012;(9):CD009379.

2. Wagoner MD. Chemical injuries of the eye: current concepts in pathophysiology and therapy. Surv Ophthalmol 1997;41: 275-313.

3. Hemmati H, Colby K. Treating acute chemical injuries of the cornea [Internet]. American Academy of Ophthalmology. 2012. Available: www. aao.org/eyenet/article/treating-acute -chemical-injuries-of-cornea (accessed 2018 Sept. 26)

4. Morgan SJ. Chemical burns of the eye: causes and management. Br J Ophthalmol 1987;71:854-7.

5. Weisenthal RW, Daly M, de Freitas D, et al. 2018-2019 Basic and Clinical Science Course (BCSC): Section 8 - External disease and cornea. San Francisco: American Academy of Ophthalmology; 2018:375-84.

Competing interests: None declared.

This article has been peer reviewed.

Affiliations: Department of Ophthalmology \& Vision Sciences (Kwok, Chew), University of Toronto; Sunnybrook Health Sciences Centre (Chew), Toronto, Ont.

Correspondence to: Hall Chew, hall.chew@utoronto.ca 